\title{
Preparedness actions towards seismic risk mitigation for the general public in Martinique, French Lesser Antilles: a mid-term appraisal
}

\author{
J. C. Audru ${ }^{1}$, J. L. Vernier ${ }^{2}$, B. Capdeville ${ }^{2}$, J. J. Salindre ${ }^{2}$, and É. Mouly ${ }^{2}$ \\ ${ }^{1}$ BRGM, French Geological Survey, Fort-de-France, Martinique, France \\ ${ }^{2}$ Directorate for Environment, Planning and Housing, Schœlcher, Martinique, France
}

Correspondence to: J. C. Audru (jc.audru@brgm.fr)

Received: 31 July 2012 - Published in Nat. Hazards Earth Syst. Sci. Discuss.: Revised: 2 July 2013 - Accepted: 7 July 2013 - Published: 15 August 2013

\begin{abstract}
Martinique is a French island in the Lesser Antilles, with a high seismic hazard. In 2006, Martinican stakeholders involved in seismic safety formed the "Réplik" working group ("Aftershock" in French), the first of its kind in this region. This paper addresses a mid-term appraisal of the first seismic awareness campaign organised by Réplik from 2006 to 2011, and how it has modified, or not, local earthquake and tsunami preparedness. Despite efforts from Réplik to assess its efficiency through surveys, a growing gap is noted between the observed awareness and the actual preparedness of the public. As usual, gender, age, educational level, then boredom and saturation contribute to this discrepancy; strong cultural items may also influence the perception of actions. To remain efficient and respond to the public's expectations, Réplik must redirect its actions towards a cultural congruence of information: consideration of religion and local beliefs, comprehensive messages on TV and radio, use of the Creole language, participatory experiences and drills, and a little science. With this, the Réplik stakeholders can hope to increase Martinicans' involvement into the preparedness process, to cope quickly with a strong earthquake and this knowhow can be shared with other seismically active islands in the Caribbean.
\end{abstract}

\section{Introduction}

Martinique Island is a French Overseas island of the Lesser Antilles archipelago, in the eastern Caribbean Sea. Martinique is located at a plate boundary (Fig. 1), above the North American plate subduction and beneath the Caribbean plate at $2 \mathrm{~cm} \mathrm{yr}^{-1}$ (Lopez et al., 2006); it was formed over
25 million yr ago by the joining together of several volcano complexes (Westercamp et al., 1989; Germa et al., 2011). This geodynamic position on top of a descending slab implies a high seismic hazard (Fig. 1): around 1000 events are detected each year, located at the subduction interface, within the Atlantic slab and the deforming Caribbean plate (Beauducel et al., 2011) but only a very few of these events are felt. The French SisFrance catalogue of historical earthquakes (BRGM, 2009) illustrates several strong MSK intensity events that have hit the island in the past: 1727 (VIII), 1827 (VII), 1839 (IX), 1946 (VII-VIII), 1999 $\left(M_{\mathrm{b}}=5.5, \mathrm{VII}\right)$ and the recent 2007 earthquake $\left(M_{\mathrm{w}}=7.4\right.$ and EMS98 int.VI-VII, see Fig. 2). Historical tsunamis are also reputed to have submerged the Atlantic coastline of Martinique (BRGM, 2010). These submersions had several origins (O'Loughlin and Lander, 2003; Lambert and Terrier, 2011): the 1755 Lisbon earthquake, the 1767 Barbados earthquake, the 1867 Virgin Islands earthquake and the 1902 Mount Pelée volcanic eruption. There is still a high concern in Martinique within public services regarding an eventual close, strong earthquake rupturing the oceanic floor at the subduction front $250 \mathrm{~km}$ off the eastern coast of Martinique.

Mainland Martinique includes a $1128 \mathrm{~km}^{2}$ mountainous island (Fig. 2). The highest point is Mount Pelée standing at $1397 \mathrm{~m}$, a large explosive volcano which last erupted in 1929 and previously in 1902, destroying the then main city of Saint-Pierre. The current population of Martinique is around 403000 inhabitants (INSEE, 2011), with one fourth living in or around Fort-de-France, the rest mostly in coastal towns (Fig. 2). 


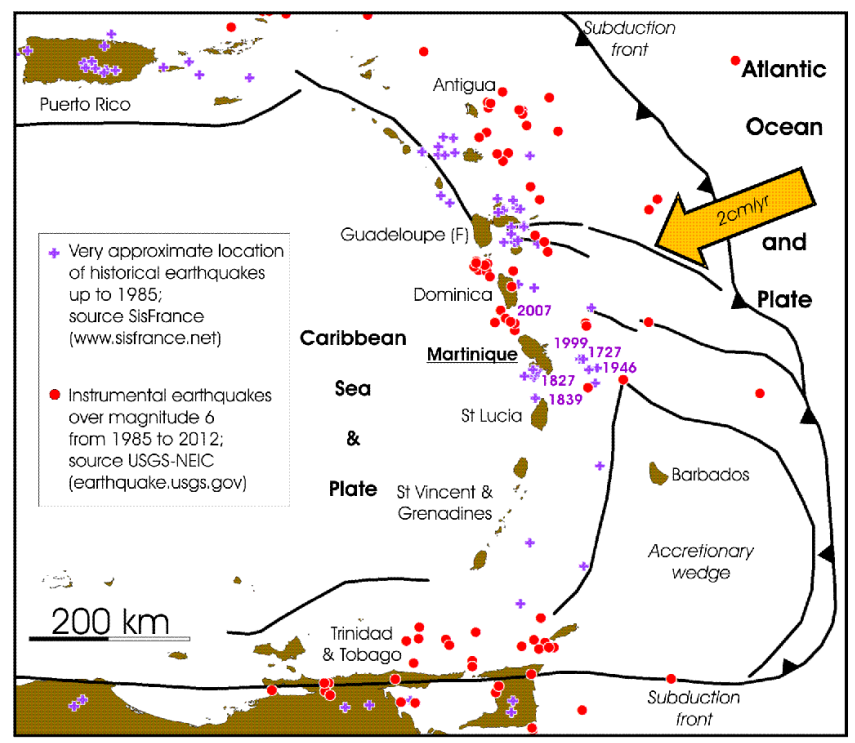

Fig. 1. Sketch map of Martinique Island within the CaribbeanAtlantic plate-boundary setting. The main regional faults and earthquakes are illustrated. The large arrow represents the motion of the Atlantic plate relative to the Caribbean plate (from Lopez et al., 2006).

In 2005, France reviewed its national seismic zonation. The highest peak ground acceleration of the territory is attributed to Martinique and Guadeloupe (PGA over $0.3 \mathrm{~g}$ for a 475 yr-return period). In 2007, the National Earthquake Plan was launched; it included the Antilles Earthquake Plan, to dedicate specific actions to Martinique and Guadeloupe, owing to their high hazard level and island specificity. The objective was to reduce the vulnerability of people and buildings in the French West Indies.

The objective of this paper is to present a mid-term appraisal of this recent and short seismic educational campaign in Martinique. A number of original actions were carried out for the first time from 2006 to 2011, and annual surveys were used to check the assimilation of actions and how these modified, or not, the preparedness of the general public (Audru et al., 2011b). Successes and failures were thus pointed out. Despite a lack of robust feedback, some hypotheses are made in this paper that may explain the observed lack of involvement into prevention actions and of preparedness. Several suggestions will be put forward to improve the preparedness process, which is essential, so that Martinique is able to cope quickly with a strong earthquake.

\section{The preparedness campaign}

Within the national plans framework, services or associations involved in seismic safety in Martinique came together into a working group called "Réplik" ("Réplik" means "Aftershock" in French) in 2006, the first of its kind and importance

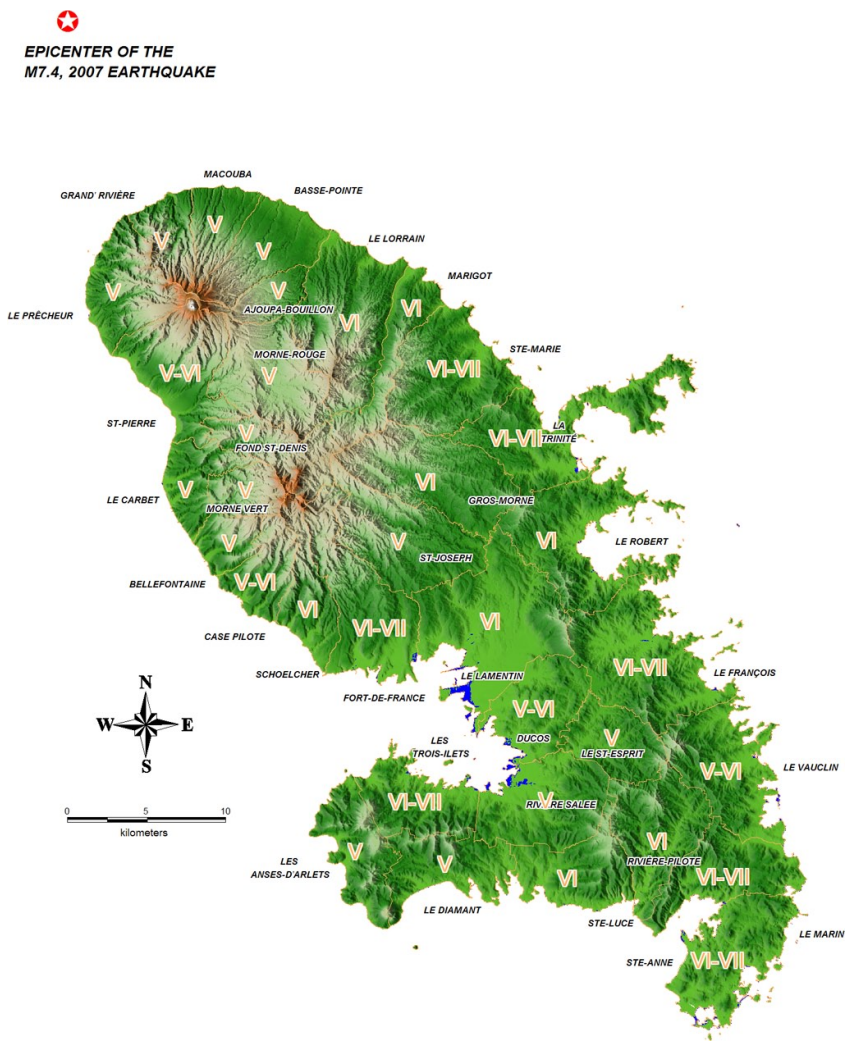

Fig. 2. The Martinique mountainous topography culminates at Mount Pelée volcano $(1397 \mathrm{~m} ; 4583 \mathrm{ft}$ ). The island is divided into 34 municipalities; Roman letters plotted into municipality areas represent the EMS98 intensities evaluated after the $M=7.4$, November 2007 slab earthquake (data from BCSF, 2008).

in this region. A logo was created which is still in use (Fig. 3). Since then, all major actions regarding public information and preparedness have been implemented and validated by Réplik, which includes state representatives, the Directorate for Environment Planning and Housing, the Association of Mayors, the Regional and General Councils, the French Geological Survey, the Civil Defence, the French Army, the Academy, the Seismological and Volcanological Observatory, the Architects Council, the Regional Health Agency, the Departmental Agency for Housing Information, the Departmental Fire and Rescue Service and several private consultants specialised in media, communication and social psychology. This diversity allows a wide array of sensibilities and ideas and favours the diffusion of messages agreed on by all partners.

Réplik's actions relating to earthquake and tsunami preparedness are characterised by events and innovations, taking place all year long but particularly in November (end of cyclonic season). These actions target residents (adults, pupils, employees, construction professionals etc.) and nonresidents (Audru, 2010). 
Actions in public areas include travelling theatre skits (how to talk about seismic preparedness with humour in various situations of contemporary life, in Creole and French), a prevention caravan and the earthquake simulator of the General Council (which allows people to learn about earthquakes' origins and to experience shaking), scientific conferences about the effects and consequences of earthquakes and tsunamis, art exhibitions related to earthquakes, information stands in annual housing fairs or hardware stores, and participation in Carnival parades. The "Réplik for Companies" action is specifically dedicated to employees and is very successful. It consists of information which is given to employees in their workplace during working hours, which is of major importance. Seismic preparedness presentations are given at the request of companies, and are adapted to workplaces and workmates, with leaflets tailored specifically to companies' working practices then being distributed.

Actions also take place in schools. Booklets are adapted to pupils, and preparedness and evacuation plans are carried out by teachers and pupils under the authority of the local education authority. In five high schools, an original project ("seismometer at school") installed seismometers for educational purposes (www.edusismo.org). The seismometers monitor the local and worldwide seismicity; recordings are operated by pupils and transmitted for computing to seismologists. The signals, downloadable for all, are then used by pupils within the framework of their curriculum.

Various goodies are distributed to remind people how to behave in the event of an earthquake or evacuate if a tsunami occurs: tee-shirts, caps, whistles, magnets, posters and brochures drawn by children, mouse pads, etc. Leaflets with instructions for safety during an earthquake have been sent by post to all families in Martinique with electricity bills. Local TV channels, cinema or radio stations are also involved in the campaign; they broadcast short spots, reality shows and cartoons of families facing earthquake situations.

Tourists arriving to Martinique are informed through short notes regarding dos and don'ts during earthquakes and tsunamis, printed on free roadmaps which are offered by hotels, tourism information desks and rental cars.

With time, the Réplik leaflets and messages gradually benefit from a wider partnership and dissemination network, usually for free: buses, pharmacies, medical offices, insurance firms, post offices, petrol outlets, commercial centres, tourism offices, etc. (Audru et al., 2011a). Examples of printed materials and media are shown in Fig. 3. Eventually, all advice, videos, leaflets, dos and don'ts related to seismic and tsunami safety from Réplik were compiled on a Martinique-specific website (www.replik972.fr). From August 2011 to July 2012, the site recorded 262000 short hits and around 22500 thirty-minute visits, which is actually not a high result.

On the neighbouring French island of Guadeloupe, a website dedicated to the self-evaluation of house seismic vulnerability (Bengoubou-Valérius, 2009) was created in

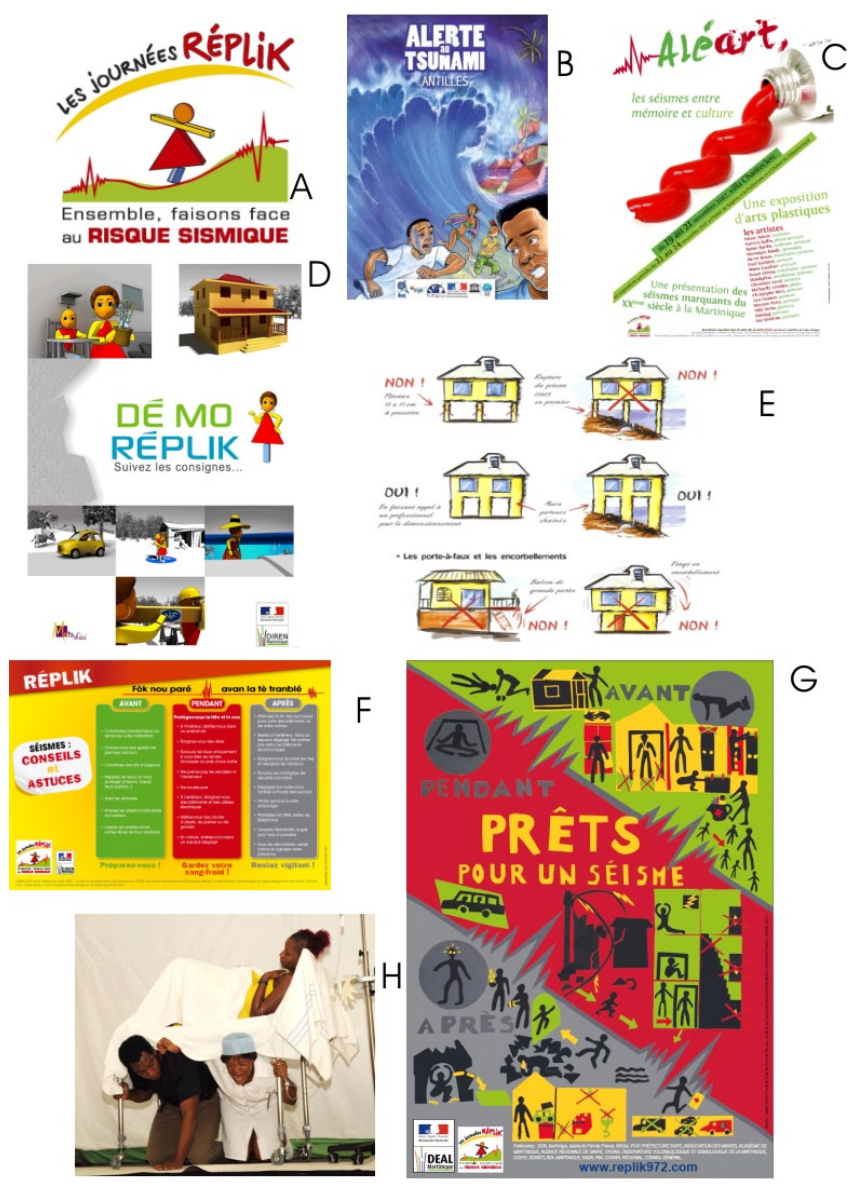

Fig. 3. Examples of Réplik information supports. (A) The Réplik logo since 2006; (B) tsunami leaflet; (C) arts exhibition "haz'arts"; (D) video series featuring a Martinican family; (E) simplified technical brochure for construction; (F) magnet with dos and don'ts; (G) instructions poster drawn by children; $(\mathbf{H})$ theatre skit of "Tranblad" which means "shaking" in Creole (featuring an authentic childbirth during the 2007 earthquake).

2011 (www.miseismantilles.com). The analysis of web traffic shows that Martinicans represent one third of visitors; among these, up to $40 \%$ of Martinique-evaluated houses prove vulnerable to earthquakes (M. Bengoubou-Valerius, personal communication, 2012). This confirms that in Martinique, many private buildings do not meet the mandatory seismic building rules in force since 1996 (French PS-92 codes), despite the strong side effects that have been evidenced since 1995 by microzonations (Gagnepain-Beyneix, 1995; Chassagneux et al., 1996 among others). This is why Réplik has also funded technical sheets and simplified building codes dedicated to traditional small-scale builders. As a complement, specific training courses are dedicated to masons regarding paraseismic building practices, based on recent and neighbours experiences (Spence, 2007; Adams, 2009). However, despite their high interest, the courses do not appeal to lots of self-employed masons (100 a year), 
probably due to the perceived loss of time involved in attending. For public buildings, past and current seismic diagnoses underline a high level of vulnerability and a large number of retrofit and reconstruction programs have been implemented.

From a scientific point of view, the Antilles Earthquake Plan encourages applied scientific studies. The regional evaluation of tsunami hazards is completed for the Caribbean French islands, using simulations based on the compilation historical scenarios (Pedreros and Terrier, 2007). Precise tsunami submersion maps are in progress, to help municipalities to organise their evacuation plan. Seismic microzonations are already in progress in several districts of Martinique following a homogeneous methodology (Monge et al., 2000; Vanoudheusden et al., 2011), as well as a predictive earthquake-induced damage evaluation for the whole island (Belvaux et al., 2013). In 2009, the

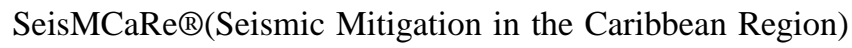
symposium (www.seismcare.com) gathered together twenty Caribbean countries in order to share know-hows, successes and failures in mitigation and education experiences between Caribbean neighbours.

Alarming results obtained from initial simulations of strong earthquake consequences (Monge et al., 2000) encouraged the authorities to organise, within the AEP framework, a wide simulation drill in 2008 which took place simultaneously in Martinique and Guadeloupe. The "Richter Antilles" drill lasted $24 \mathrm{~h}$ and tested several topics (Cova, 2009) such as the coordination of rescue services, management dysfunctions (population, lifelines, and casualties), national reinforcements, and management of deceased people. The drill marked a turning point for such simulation exercises in France (Winter et al., 2009).

Despite this wide array of preparedness actions from 2006 to 2011, a question rapidly arises: what is the actual impact and effectiveness of this educational campaign among the population? The question is important, almost vital, given the historical records and the high seismic and tsunami hazard threatening Martinique.

\section{The public's general perception of preparedness actions}

\subsection{Methodology}

The perception of preparedness actions by the public does not benefit from a strong history and feedback. It is approached through the analysis of five short surveys conducted in Martinique in various conditions in 1999, then from 2006 to 2010 (Fig. 4). The 1999 survey was conducted by the University of the French West Indies after the 1999 earthquake; the last four were organised by a specialised polling company under Réplik request. The surveys structures remained quite simple; detailed information about the data collection process, questionnaires and analysis is available from the author on request.

\subsection{Results}

The 1999 survey occurred within ten days following the 5.5 earthquake. The authors (Léone and Mavoungo, 2000) telephoned 224 people who were standing in buildings during the event. The analysis of their answers outlined that $75 \%$ of those surveyed described inappropriate behaviour during the event and $64 \%$ after the event; later on, only $22 \%$ of those surveyed took preparedness measures. The people surveyed had then expressed high expectations in terms of information and preparation advice.

In 2006, a second survey was conducted among 334 Martinican visitors to the itinerant earthquake simulator. Colbeau-Justin et al. (2007) had outlined that most of the visitors $(72.5 \%)$ proved interested in safety measures, especially in terms of technical aspects $(49 \%)$ rather than scientific aspects; the latter being considered useless for individual protection. Women showed more interest $(60 \%)$ in the correct behaviour to adopt during an earthquake, in the reliability of the home interior and in the preparation of survival kits, while men $(40 \%)$ were interested in technical skills (construction, first aid certificates).

The survey also evidenced the public's preference for an immediate response organisation (as opposed to postcrisis planning) via TV $(65 \%)$, rather than through written brochures $(31.5 \%)$, insets in newspapers, scientific conferences or neighbourhood meetings, which was indeed common to several countries (Spence, 2007). On this basis, Colbeau-Justin et al. (2007) suggested that Martinicans preferred personal learning experiences and visual demonstrations, which explains the continuing success of the earthquake simulator and of the itinerant theatre. This use of a few media for addressing prevention actions is also preferred in Turkey for instance (Tekeli-Yeşil et al., 2011). The malefemale dichotomy is observed elsewhere (Mulilis, 1999; Solberg et al., 2010), from a detailed lecture of the related psychological literature, suggest that experience, gender and also age can shape risk perception and thus a campaign's successes or failures. The above analysis encouraged Réplik to prepare TV spots and cartoons featuring a woman preparing her family for a potential earthquake.

The 2007 survey followed the 7.4 earthquake (which occurred one month before). This poll (computer-assisted telephone interviews) of 1050 Martinicans (Ipsos Antilles, 2008) aged over 15 who felt the earthquake, revealed that $63 \%$ of people judged themselves sufficiently informed, while $68 \%$ had heard about Réplik's actions. The analysis showed that $62 \%$ knew how to behave during the earthquake and $70 \%$ believed they had appropriate behaviour during the event. Indeed, only $20 \%$ of people had immediately exited buildings, $21 \%$ moved away from building facades, $19 \%$ had listened to the radio and $2-3 \%$ had cut electricity and gas. 

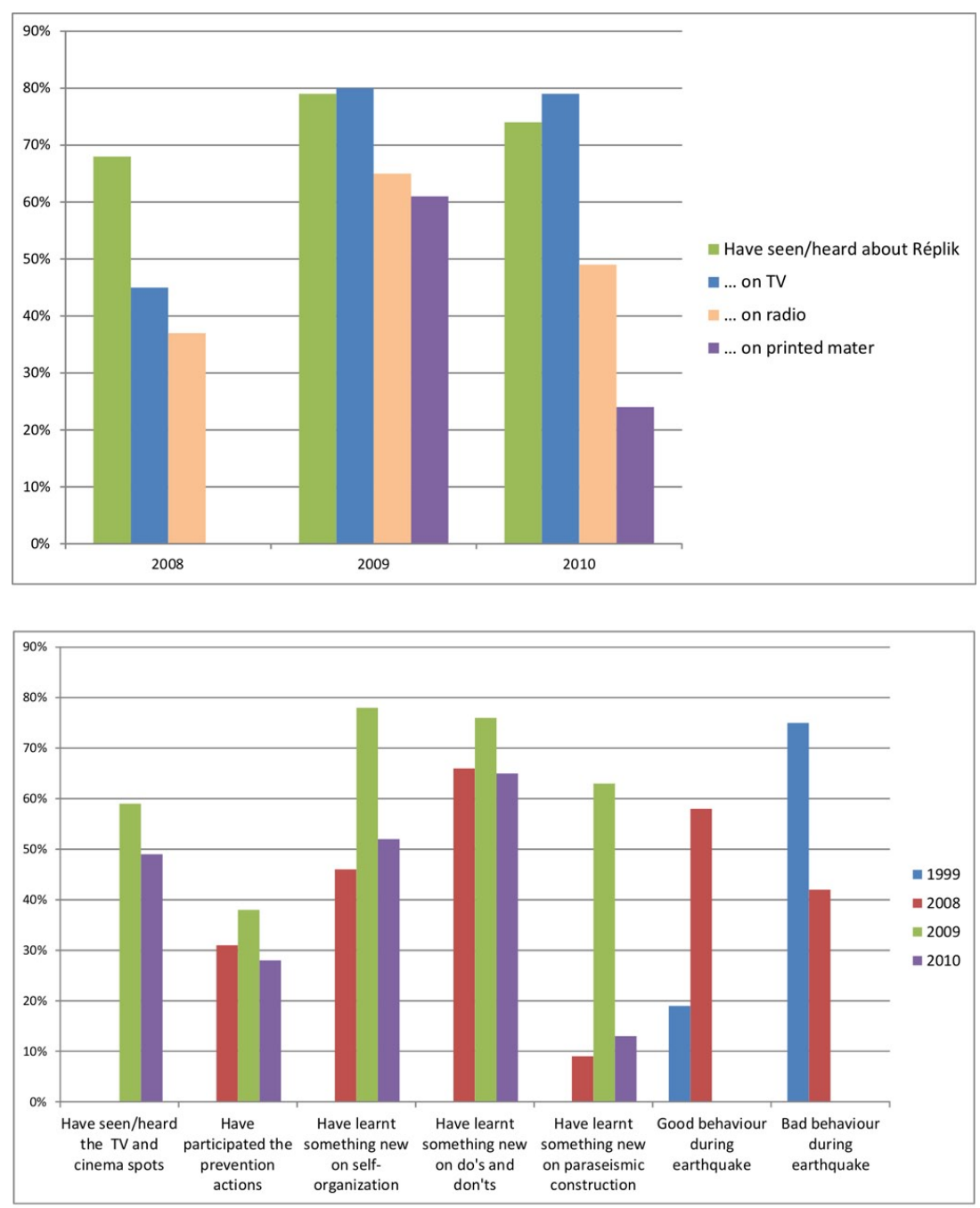

Fig. 4. Evolution of awareness and of several preparedness topics among successive polls within the Martinique population from 1999 to 2010. (A) Notoriety of Réplik actions; (B) perception of prevention and preparedness actions.

On the contrary, $42 \%$ of people inside buildings had inadequate responses: $41 \%$ used stairs to exit buildings during the shaking, $38 \%$ remained inside buildings after the first shock, $39 \%$ used a cellular phone and $36 \%$ entered back into the buildings shortly after the main shock. More educated people and those younger than 36 were much more aware of the reality of risk (89\%) than elderly or less educated people $(69 \%)$, who were less affected by communication campaigns. The survey showed that appropriate instructions given by Réplik were mostly known, but were rarely enforced. People's knowledge was affected by surprise, fear and even panic for some, preventing them from behaving in an appropriate way (Ipsos Antilles, 2008). Finally, only 3 to $18 \%$ of Martinicans, mainly those under the age of 36 , spontaneously said they would enhance their preparedness, these values went up to $71 \%$ when people were told what sort of action to take (survival kits, home security, seismic drills etc.).

In 2009, a fourth survey (Ipsos Antilles, 2009) tested the response to actions developed through Réplik in 2008, in order to assess the impact of the modified campaign. The survey of 503 people living in Martinique (computer-assisted telephone interviews) showed that awareness of Replik increased to $79 \%$ of the public, especially among women. This was mainly due to the strong emphasis placed on TV cartoons (seen by $79.9 \%$ ) and radio spots (heard by $64.6 \%$ ) with the involvement of local popular personalities (singers, writers, the archbishop etc.) and of the prevention caravan $(9 \%)$. The perception of dos and don'ts in building codes increased in up to $54 \%$ of the public. TV and radio remained the best dissemination channels, even if their audience decreased by $10 \%$ compared to 2007 . The toll-free information phone number got very few calls $(1 \%)$ and was then 
abandoned. This survey revealed that the 2007 earthquake experience increased preparedness for a while, as observed in other studies (Dooley et al., 1992; Nguyen et al., 2006), but with variable impact, maybe depending on 2007 material losses, as observed elsewhere (Lindell and Perry, 2000), or most probably on individuals' unrealistic estimations of their own ability to cope with the consequences of an earthquake (Colbeau-Justin, 2009).

The last Réplik survey occurred in 2010 (Ipsos Antilles, 2010). This poll (computer-assisted telephone interviews) of 509 Martinicans outlined a decrease in Réplik awareness to $74 \%$ of respondents (Fig. 4). The participation in prevention actions decreased considerably, with the exception of the theatre skit (11\%), illustrating either a good knowledge of correct behaviours or saturation or even public boredom regarding preparedness actions (Audru et al., 2011a). Respondents found the actions' content less relevant than previous years. The TV (79\%) and the radio (49\%) remained the best communication vectors, far above printed materials $(11 \%)$ and internet information channels $(3 \%)$. This latter information highlights the difference of culture to cope with, in earthquake prevention, with internet being a much more promising dissemination technique for Turk people for instance (Tekeli-Yeşil et al., 2011) than for Martinicans. The observed decrease in people's interest through this survey suggests that inadequate actions and messages were presented at some time during the 2010 Réplik campaign: these factors decrease people's knowledge (Johnston et al., 2005), as does the frequency of the messages, (Mileti and Fitzpatrick, 1992) which can alter risk awareness and contribute to the persistence of inadequate behaviour.

A parallel survey conducted through the housing selfevaluation website confirmed that in both Guadeloupe and Martinique, $75 \%$ of people know the dos and don'ts regarding earthquake safety; however, only $20 \%$ say that they are "earthquake-ready" and $32 \%$ have prepared a survival-kit (M. Bengoubou-Valerius, personal communication, 2012). These values are close to the 2008 post-earthquake survey and may reflect an inappropriate self-estimation of preparedness.

\section{Discussion}

Martinican respondents to the surveys generally have a high level of knowledge about the possible occurrence of strong earthquakes or tsunamis. As an encouraging result, Réplik's actions have significantly raised an interest and its set points were known by $80 \%$ of the public in Martinique in 2010. However, the surveys outline a discrepancy between those who are aware and those who actually prove able to cope with earthquake or tsunami consequences. Considerable efforts must still be made to reinforce people's involvement. Which hypotheses can be made to explain the obstacles and what are the perspectives?
A first hypothesis is based on daily life in Martinique, which is strongly influenced by fatalism. It is anchored in religion but also in magical beliefs or superstitions which have been inherited from the population's African, European and Amerindian origins (Léti, 2000): "Quimbois", for instance, comprises practices related to magic and sorcery very similar to "Voodoo" in Haiti (Revert, 1951). Indeed, beliefs like "earthquakes occur during the hot season", "talking about earthquakes makes them occur", "the island will sink" and "the island will be cut in half" are still common (Léone and Mavoungo, 2000; Sarant et al., 2004; Colbeau-Justin et al., 2007). Regarding religion, up to $13 \%$ of people interviewed for the 2008 survey attribute a divine origin to earthquakes, mainly those over $55 \mathrm{yr}$ of age and people not having been to high school (Ipsos Antilles, 2008). Magical beliefs and religion, as an important element of the Martinican culture, have not been explored through surveys yet. At this stage, although no one knows to what extent yet, one can make the hypothesis that such popular beliefs and religion decrease the actual perception of the threat by misrepresenting the actual consequences of an earthquake in Martinique, as observed in other regions (Turner et al., 1986). It implies that nothing can be done to protect oneself and it clearly influences individuals' involvement; this inhibits or slows down citizens' engagement in preventative practices and preparedness actions (Turner et al., 1986; Paton et al., 2005). This is probably the reason why, in survey answers, the possible consequences of earthquakes are never clearly described by people and therefore are not clearly anticipated and, even less, prepared for. These cultural and religious considerations have to be much more included in the next Réplik phase, in order to increase the effectiveness of prevention (Chester, 2005; Chester et al., 2008). Solberg et al. (2010) argue that the preparedness sources of information have to be strongly culturally congruent with the general public in order to be fully trusted and accepted. A role may be given to the clergy (Chester, 1985) to help overcome the perception of the divine and inevitable consequences of earthquakes and tsunamis. The inclusion of much more local culture into the preventative actions of an efficient preparedness plan is also supported by Tanaka (2005) or either the United Nations (2005).

Another hypothesis is that messages are not correctly formatted. Martinican and Turkish surveys for instance (TekeliYeşil et al., 2011) highlight similar knowledge and preparedness attitudes according to socioeconomic factors and educational level. Tekeli-Yeşil et al. (2011) or Barooah (2006) in India both favour preparedness programmes carried out by the media to target weaker people characterised by lower educational and socio-economic levels. Nathe et al. (1999), then Olshansky (2005), give simple guides to reaching these ambitious objectives as part of an efficient long-haul campaign: clear messages using common, comprehensive words, tailored for specific audiences, sent through modern media and a wide partnership network. An unusual approach is given by Paton et al. (2005) who define three successive 
stages of preparedness: motivation to prepare, formation of intentions, and the conversion of intentions into actions. People progress to the next phase under relatively high (but appropriate, see Lamontagne and La Rochelle, 2000) levels of hazard anxiety. Specific strategies form a step from one stage to another, for example information targeted to a specific community, as cited by Tekeli-Yesil et al. (2011) above. Weiss et al. (2011) promote the perspective of a more participatory communication for the prevention of natural hazards.

A third hypothesis states that science is not in a good position in the campaign. People show very little interest in science because it does not help them in practical prevention actions (rescue kits, furniture etc.). Despite the low levels of audience interest, science may still have a role to play. According to Lamontagne and La Rochelle (2000), seismologists should follow psychological courses to help and support the public's emotional reactions before or after an earthquake. Scientists should also participate in communication plans which include concrete facts about earthquakes, to anticipate the event and its associated anxiety (Lamontagne, 1992; McClure et al., 1999). Science can at least promote up-to-date scientific ideas instead of fakes and rumours disseminated by local beliefs or the internet.

These hypotheses regarding local and cultural factors may explain the failures in Réplik's campaign. Our set of observations, despite its brevity and despite the simple surveys, favours new prevention axes for Martinique. The second phase of the Antilles Earthquake Plan will begin in 2013 and will offer the opportunity to test these hypotheses and to redirect Réplik's actions.

First, a survey would specifically explore the weight of beliefs and religion in the representations of earthquakes and tsunamis in Martinique. This will allow a tailored response to Martinicans' demands and needs, in accordance with most recent UN advice (United Nations, 2005). The use of much more Creole language in media and messages could help overcome the cultural beliefs, the barrier of fatalism and the disinterest in basic science. Such a redirection may help people to take an extra step towards the preparedness process of Paton and overcome their subjective representations.

Then emphasis should be put on the answer to the growing demand for practical skills: individual short training courses for adults and pupils (first aid courses, appropriate behaviour at home, outside, at work, at the seaside etc.), home security (furniture organisation and securing, rescue kits for homes, work and cars etc.). TV and radio will be the privileged vectors.

In Martinique, the community network is very dense, due to the small space formed by the island and to the numerous interconnections between families. This community strength should be used to increase hazard preparedness, following Paton et al. (2010), who suggest that mainstream community activities can increase the likelihood of developing preparedness among neighbours. The organisation of participatory experiences (neighbourhood solidarity, earthquake simulators, seismic and tsunami drills in suburbs, towns or at work, etc.) is to be encouraged. The creation of a special day dedicated to an historical or recently felt earthquake would be another opportunity for community actions, following the model of "shakeout" drills (www.shakeout.org) initially organised by the Earthquake Country Alliance of California (2003).

On a technical point of view, the training courses and booklets for building professionals have to be strongly simplified for small builders or individual masons in order to attract more such artisans, using another similar experience (Adams, 2009). Simplifications should help to avoid misunderstandings and comply with vernacular traditions (Spence, 2007), demonstrations of the techniques in the field would be extended to ensure a more successful course (Leslie, 1984).

\section{Conclusions}

At the beginning of the Réplik campaign in 2006, public awareness was quite low in Martinique despite historical events and recent earthquakes. The Réplik actions significantly raised an interest and its set points are now known by most of Martinicans, especially through TV and radio, which prove the most efficient vectors. However, despite efforts on the part of the Réplik group to assess the efficiency of educational actions, this paper outlines a growing gap between the observed awareness and the actual preparedness of the public. As usual, gender, age, educational level, boredom, saturation, but also Martinique's culture may explain this discrepancy.

To remain attractive and efficient and to respond to the public's expectations and needs, Réplik has to upgrade its appeal. An opportunity lies in the coming second phase of the Antilles Earthquake Plan, to anchor existing actions or successful overseas experiences much more into local culture: consideration of cultural beliefs and religion to maintain the congruence with information, use of the Creole language, specific education to specific people, participatory experiences, seismic and tsunami drills, with a little science to maintain a moderate level of knowledge. This is thought to increase people's involvement in the construction of preparedness. Thus, one can hope that Martinique will rapidly be able to cope with a strong earthquake, and this know-how will benefit other seismically active islands in the Caribbean.

Acknowledgements. The authors wish to thank the French Ministry for Environment, the Martinique Directorate for Environment, Planning and Housing and the French Geological Survey (BRGM) for supporting and funding this paper. This study is a part of the long-term Réplik joint venture gathering Martinican communities and stakeholders; both are also thanked for their implication in seismic safety in Martinique. The authors are finally grateful to their referees, to D. Paton, K. Tanaka and S. Tekeli-Yeşil for their highly constructive comments on our initial manuscript. All cited open file BRGM reports are freely downloadable from 
www.brgm.fr and numerical matter from Réplik is available from the authors on request. The paper is dedicated to Jean-Pierre Doudic.

Edited by: T. Glade

Reviewed by: S. Tekeli-Yesil, D. Paton, and K. Tanaka

\section{References}

Adams, G.: The safer building programme in the UK Virgin Islands, in: proceedings of the SeismCaRe conference, Schœlcher, Martinique, 2009.

Audru, J. C.: Los canales de información pública sobre el riesgo sísmico en Martinica, Antillas Francesas, UN-ISDR Informs Journal, 17, 2010 (in English and Spanish).

Audru, J. C., Capdeville, B., Salindre, J. J., and Nérée, N.: Actions towards seismic risk mitigation in Martinique, French Antilles, in: proceedings of the 19th Caribbean Geological Conference, Le Gosier, Guadeloupe, 2011a.

Audru, J. C., Belvaux, M., Bengoubou-Valerius, M., Bertil, D., Mompelat, J. M., and Roullé, A.: Seismic hazard status and mitigation actions in Guadeloupe and Martinique, French West Indies, in: proceedings of the 6th Caribbean Conference on Comprehensive Disaster Management proceedings, Port of Spain, Trinidad and Tobago, 2011b.

Barooah, P. R.: Capacity building for earthquake safety and mitigation through awareness and community education, in: proceedings of the First European Conference on Earthquake Engineering and Seismology, Geneva, Switzerland, 2006.

BCSF, Bureau Central Sismologique Français: Séisme de Martinique, 29 novembre 2007, synthèse sismologique et étude macrosismique, Openfile BCSF report, 132 pp., 2008 (in French).

Beauducel, F., Bazin, S., Bengoubou-Valérius, M., Bouin, M. P., Bosson, A., Anténor-Habazac, C., Clouard, V., and De Chabalier, J. B.: Empirical model for rapid macroseismic intensities prediction in Guadeloupe and Martinique, C. R. Geosci., 343, 717-728, 2011.

Belvaux, M., Monfort-Climent, D., Bertil, D., Roullé, A and Noury, G.: Cartographie départementale du risque sismique en Martinique, Openfile BRGM report RP-61904-FR, 2013 (in French).

Bengoubou-Valérius, M.: Development of an Internet tutorial for self-assessment of the seismic vulnerability of individual houses in the French West Indies, in: Proceedings of the SeismCaRe conference, Schœlcher, Martinique, 2009.

BRGM, French geological survey: SisFrance website for historical earthquakes in the Antilles and the Caribbean region, available at: www.sisfrance.net/Antilles (last access: 2013), 2009.

BRGM, French geological survey: Official website for historical tsunamis in France, available at: www.tsunamis.fr (last access: 2013), 2010.

Chassagneux, D., Martin, C., Monge, O., Samarcq, F., and Sedan, O.: Microzonage sismique des communes de Schoelcher, Fortde-France et Le Lamentin: effets de site et liquéfaction, Openfile BRGM report RR-39186-FR, 1996 (in French).

Chester, D. K.: Theology and disaster studies: The need for dialogue, J. Volcanol. Geoth. Res., 146, 319-328, 2005.

Chester, D. K., Duncan, A. M., and Dibbenc, J. J. C.: The importance of religion in shaping volcanic risk perception in Italy, with special reference to Vesuvius and Etna, J. Volcanol. Geoth. Res., 172, 216-228, 2008.

Colbeau-Justin, L.: How to deal with the safety needs of people at seismic risk?, in: Proceedings of the SeismCaRe conference, Schœlcher, Martinique, 2009.

Colbeau-Justin, L., Cartier, S., and Weiss, K.: Le risque sismique en Martinique, de sa perception à son intégration dans des pratiques préventives, Plan National de Prévention du Risque Sismique, Journées Réplik, technical note, 2007 (in French).

Cova, P.: Earthquake crisis simulation exercise in the French Antilles: methods and experience feedback, in: Proceedings of the SeismCaRe conference, Schœlcher, Martinique, 2009.

Dooley, D., Catalano, R., Mishra, S., and Serxner, S.: Earthquake preparedness: predictors in a community survey, J. Appl. Soc. Psychol., 22, 451-470, 1992.

Earthquake Country Alliance of California: internet website, available at: www.earthquakecountry.info (last access: 2012), 2003.

Gagnepain-Beyneix, J., Lépine, J. C., Nercessian, A., and Hirn, A.: Experimental study of site effects in the Fort-de-France area (Martinique Island), B. Seismol. Soc. Am., 85, 478-495, 1995.

Germa, A., Quidelleur, X., Labanieh, S., Chauvel, C., and Lahitte, P.: The volcanic evolution of Martinique Island: Insights from $\mathrm{K}-\mathrm{Ar}$ dating into the Lesser Antilles arc migration since the Oligocene, J. Volcanol. Geoth. Res., 208, 122-135, 2011.

INSEE (French institute for statistics and economic studies): Recensement de la population et Populations légales en vigueur à compter du 1er janvier 2012 en Martinique, 2011 (in French).

Ipsos Antilles (polling company): Étude Réplik et Séisme du 29 novembre 2007, 2008 (in French).

Ipsos Antilles (polling company): Enquête de notoriété et d'impact des journées Réplik 2008, 2009 (in French).

Ipsos Antilles (polling company): Enquête d'opinion sur les 5èmes journées Réplik auprès du grand public Martiniquais, 2010 (in French).

Johnston, D., Paton, D., Crawford, G. L., Ronan, K., Houghton, B., and Bürgelt, P.: Measuring Tsunami Preparedness in Coastal Washington, United States, Nat. Hazards, 35, 173-184, 2005.

Lambert, J. and Terrier, M.: Historical tsunami database for France and its overseas territories, Nat. Hazards Earth Syst. Sci., 11, 1037-1046, doi:10.5194/nhess-11-1037-2011, 2011.

Lamontagne, M. and La Rochelle, S.: Earth scientists can help people who fear earthquakes, Seismol. Res. Lett., 71, 461-463, 2000.

Lamontagne, M., Du Berger, R., and Stevens, A. E.: Seismologists can help attenuate post-earthquake public vibrations, Earthq. Spectra, 8, 573-594, 1992.

Léone, F. and Mavoungo, J.: Le séisme du 8 juin 1999 de la Martinique, résultats de l'enquête post-sismique sur les personnes se trouvant dans les bâtiments, Département GEODE, Note technique de l'Université des Antilles et de la Guyane, 2000 (in French).

Leslie, J.: Think before you build: an earthquake reconstruction project in Yemen, in: proceedings of the International Symposium on Earthquake Relief in Less-industrialised Areas, Zurich, Switzerland, 1984.

Léti, G.: L'univers magico-religieux antillais, ABC des croyances et des superstitions d'hier et d'aujourd'hui, Eds. L'harmattan, Paris, 2000 (in French). 
Lindell, M. K. and Perry, R. W.: Household adjustment to earthquake hazard: a review of the research, Environ. Behav., 32, 461$501,2000$.

Lopez, A., Stein, S., Dixon, T., Sella, G., Calais, E., Jansma, P., Weber, J., and La Femina, P.: Is there a northern Lesser Antilles forearc block? Geophys. Res. Lett., 33, L07313, doi:10.1029/2005GL025293, 2006.

McClure, J., Walkey, F., and Allen, M.: When earthquake damage is seen as preventable: attributions, locus of control and attitudes to risk, Appl. Psychol., 48, 239-256, 1999.

Mileti, D. S. and Fitzpatrick, C.: The causal sequence of risk communication in the Parkfield earthquake prediction experiment, Risk Anal., 12, 393-400, 1992.

Monge, O., Bour, M., Lebrun, B., Leroi, E., Mirgon, C., Sedan, O., Mompelat, J. M., Martin, C., Souloumiac, R., and Chauvel, F.: Seismic risk assessment at both urban and regional scales in the French Lesser Antilles, methods and results, in: Proceedings of the 12th World Conference on Earthquake Engineering, New Zealand, 2000.

Mulilis, J. P.: Gender and earthquake preparedness. A research study of gender issues in disaster management: differences in earthquake preparedness due to traditional stereotyping or cognitive appraisal, Aust. J. Emerg. Manag., 14, 41-50, 1999.

Nathe, S., Gori, P., Greene, M., Lemersal, E., and Mileti, D.: Public education for earthquake hazards. Univ. of Colorado, Natural Hazards Center, Informer Issue 2, 1-12, 1999.

Nguyen, L. H., Haikang S., Ershoff, D., Afifi, A. A., and Bourque, L.: Exploring the causal relationship between exposure to the 1994 Northridge Earthquake and pre- and post-earthquake preparedness activities, Earthq. Spectra, 22, 569-587, 2006.

O'Loughlin, K.-F. and Lander, J.-F.: Carribbean tsunamis, a 500Year History from 1498-1998, Adv. Nat. Technol. Haz. Res., 263 pp., 2003.

Olshansky, R. B.: Making a difference: stories of successful seismic safety advocates, Earthq. Spectra, 21, 441-464, 2005.

Paton, D., Smith, L. M., and Johnston, D.: When good intentions turn bad: Promoting natural hazard preparedness, Aust. J. Emerg. Manag., 20, 25-30, 2005.

Paton, D., Bajek, R., Okada, N., and McIvor, D.: Predicting community earthquake preparedness: a cross-cultural comparison of Japan and New Zealand, Nat. Hazards, 54, 765-781, 2010.
Pedreros, R. and Terrier, M.: Étude préliminaire de l'aléa tsunami aux Antilles françaises, Openfile BRGM report RR-55792-FR, 2007 (in French).

Revert, E.: La magie antillaise, Paris, Éds. Bellenand, 203 pp., 1951 (in French).

Sarant, P. M., de Vanssay, B., Colbeau-Justin, L., and Flagie A.: Satisfaction résidentielle et perceptions du risque sismique chez les résidents d'habitat social en Guadeloupe, DDE Guadeloupe, Secteur pilote d'innovation outre-mer, technical note, 2004 (in French).

Solberg, C., Rossetto, T., and Joffe, H.: The social psychology of seismic hazard adjustment: re-evaluating the international literature, Nat. Hazards Earth Syst. Sci., 10, 1663-1677, doi:10.5194/nhess-10-1663-2010, 2010.

Spence, R.: Saving lives in earthquakes: successes and failures in seismic protection since 1960, B. Earthq. Eng., 5, 139-251, 2007.

Tanaka, K.: The impact of disaster education on public preparation and mitigation for earthquakes: a cross-country comparison between Fukui, Japan and the San Francisco Bay Area, California, USA, Appl. Geog., 25, 201-225, 2005.

Tekeli-Yeşil, S., Dedeoğlu, N., Braun-Fahrlaender, C., and Tanner, M.: Earthquake awareness and perception of risk among the residents of Istanbul, Nat. Hazards, 59, 427-446, 2011.

Turner, R. J., Nigg, J. M., and Paz, D. H.: Waiting for Disaster: Earthquake Watch in California. Los Angeles, California, University of California Press, 1986.

United Nations: Report on the World Conference on Disaster Reduction, Kobe, Hyogo, Japan, 18-22 January 2005, United Nations, Geneva, 2005.

Vanoudheusden, É., Roullé, A., and Barras, A. V.: Seismic microzonation of a municipality in French West Indies, in: proceedings of the 18th Caribbean Geological Conference, Le Gosier, Guadeloupe, 2011.

Weiss, K., Girandola, L., and Colbeau-Justin L.: Les comportements de protection face au risque naturel: de la résistance à l'engagement, Prat. Psychol., 17, 251-262, 2011 (in French).

Westercamp, D., Andreieff, P., Bouysse, P., Cottez, R., and Battistini, R.: 1/50 000 geological map of Martinique and its notice, BRGM Eds., 1989 (in French).

Winter, T., Bes de Berc, S., Cova, P., Sedan, O., Audru, J. C., and Terrier, M.: Méthodologie pour la réalisation d'un exercice de crise sismique de type Richter. Open file BRGM report RP57237-FR, 2009 (in French). 